\title{
UNCERTAINTIES ON VS PROFILES AND SITE RESPONSE AT A VERTICAL STRONG MOTION ARRAY
}

\author{
Makra K. ${ }^{1}$ and Raptakis D. ${ }^{2}$ \\ ${ }^{1}$ Institute of Engineering Seismology and Earthquake Engineering EPPO-ITSAK, 55535 \\ Thessaloniki, Greece, makra@itsak.gr \\ ${ }^{2}$ Aristotle University of Thessaloniki, Department of Civil Engineering, 54124 Thessaloniki, \\ Greece,raptakis@auth.gr
}

\begin{abstract}
We present a detailed study of various shear wave velocity, $V_{S}$, profiles at TST site of Euroseistest test-site. We benefit from the availability of $62 V_{S}$ models derived from seismic interferometry, stress-strain analysis and annealing simulation based on earthquake data, conventional seismic prospecting (surface wave inversion, crosshole and downhole tests), and seismic noise array measurements, that when grouped in five lead to corresponding averaged $V_{S}$ profiles. The estimate of $V_{S}$ models differs depending on the technique used. The observed disparity with respect to the average reference model, albeit small, becomes significant at certain depths and is associated with the existence of strong vertical discontinuities, introducing an uncertainty on the interface definition between the main formations. Results from site amplification study, based on these profiles, show an analogous uncertainty leading to a certain underestimation with respect to the reference model, which should be treated with caution when engineering applications are involved.
\end{abstract}

Keywords: interferometry, stress-strain, seismic noise, prospecting.

\section{Пєрí $\lambda \psi \eta$}

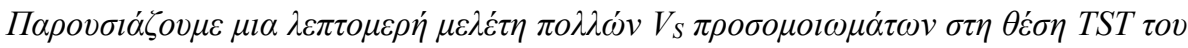

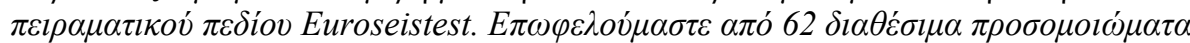

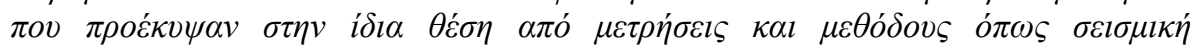

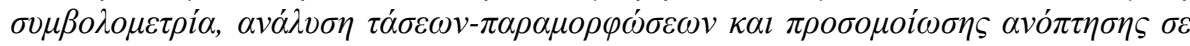

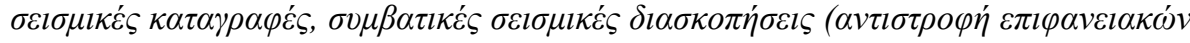

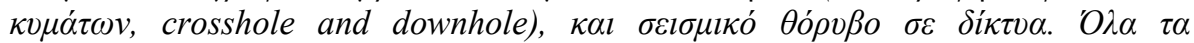

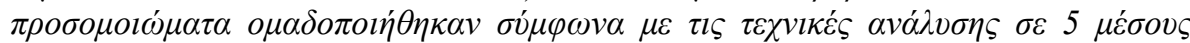

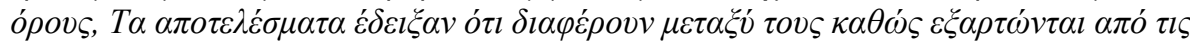

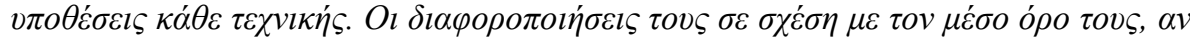

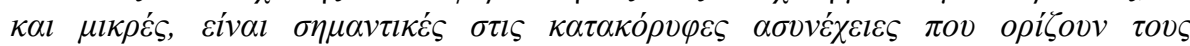

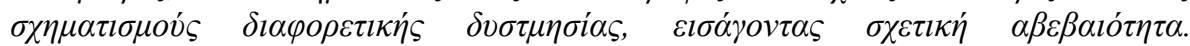

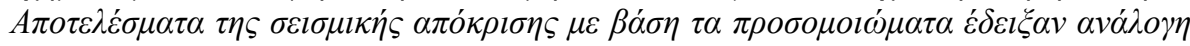

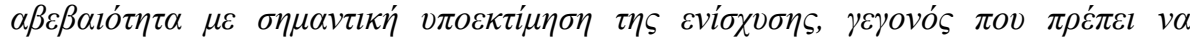

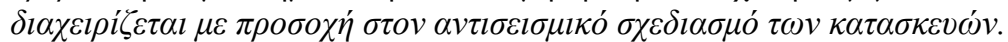

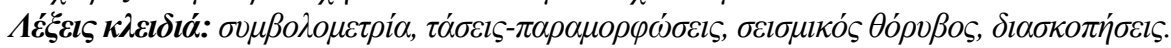




\section{Introduction}

Shear wave velocity $\left(\mathrm{V}_{\mathrm{S}}\right)$ is deemed the most important parameter in earthquake engineering and engineering seismology studies. Its knowledge is useful for site effect estimations (e.g. Borcherdt, 1970; Aki, 1988; Bard, 1994 and Chávez-García, 2011), seismic hazard assessment and Ground Motion Prediction Equations (e.g. Boore, 2004; Abrahamson et al., 2008 and Douglas et al., 2009), microzonation and other site specific studies in geotechnical engineering (i.e. liquefaction, soilfoundation-structure interaction etc.). On the other hand, the exploration of Vs velocity is a rather non-straightforward task due to the nature of the demands of the anticipated study and its non-unique evaluation from different techniques (for details see also Raptakis, 2012, 2013 and Raptakis and Makra, 2015). Then, in such cases of different $V_{S}$ estimates available at a site, it is necessary to understand the differences and not simply compute an average.

Currently, a set of non-invasive and invasive techniques were applied, in order to get at one site, TST, at the center of a rather shallow basin known as Mygdonian basin or EUROSEISTEST site (Jongmans et al., 1998; Raptakis et al., 2000, 2005; Manakou et al., 2010; Chávez-García et al., 2014; Hannemann et al., 2014), the $\mathrm{V}_{\mathrm{S}}$ profile intended to satisfy different kinds of studies, with special emphasis, though, to site response evaluation. For the purpose of this study, 62 estimated $V_{S}$ profiles are analysed, their differences are reviewed, and averaged profiles are compared to each other. The result is a combined model of sediments $V_{S}$ until intact bedrock $\left(V_{S} \sim 3200 \mathrm{~m} / \mathrm{s}\right)$ at depth of several hundreds of meters, used as a reference one. Hereafter, the averaged Vs profiles are used to evaluate their site response characteristics in a framework of preliminary study.

\section{Vs profiles at TST site}

The site under study is situated in the centre of EUROSEISTEST (Mygdonian) basin. A huge amount of geotechnical and geophysical surveys has been deployed at this test site during the last 22 years including seismic prospecting methods, microtremor measurements, and in-situ and laboratory geotechnical tests. The final outcome of this effort was initially a 2D soil model (Raptakis et al., 2000 and Raptakis et al., 2005) and recently a 3D structure (Manakou et al., 2010). Especially, at TST where a deep 3-component accelerometers down-hole array has been installed, all measurements and analyses are gathered in an effort to build the most precise and accurate possible soil model. This vertical array (www.dbseis.civil.auth.gr, Pitilakis et al., 2013) consists of 6 accelerometers; at surface, 18.7, 40, 73.1, 136 and $196 \mathrm{~m}$ depths; the last located at sedimentsbedrock interface with common trigger, absolute time as well as orientation control of the horizontal components. The analyses of DH earthquake recordings result to shear wave velocity profiles of the sedimentary formations and are presented herein together with $\mathrm{V}_{\mathrm{S}}$ profiles from conventional seismic prospecting and array noise measurements.

Seismic interferometry technique (CC). Recordings from 8 earthquakes at the vertical accelerometric array were used to determine $V_{S}$ velocity of soil layers (figure 1a) using seismic interferometry of ground motion (Raptakis and Makra, 2015). Raw data have been corrected for instrument response and baseline offset. The horizontal components of the recordings, of casual but known orientation, are rotated to derive the radial and transverse components of motion with respect to the basin shape. Both horizontal components of motion at each station are cross-correlated using the deepest station, at $196 \mathrm{~m}$, as reference. The results, phase velocity derived from the pronounced very onset first $\mathrm{S}$-wave arrival, are quite stable with small standard deviation (less than $8 \%$ ) despite that data used come from earthquakes with different azimuths, epicentral distances and focal depths, parameters that may affect the vertical near surface propagation of body waves. The small scatter is related with the use of a single point-phase of the signals. The similarity of $\mathrm{V}_{\mathrm{S}}$ velocities between horizontal components does not suggest any significant anisotropy effect, thus an average of both components can be considered representative at the site, for this method.

Stress--strain $(\tau-\gamma)$ analysis (SS). Six earthquake recordings at the vertical array used to define 
the stiffness of sediments in an alternative way with stress-strain $(\tau-\gamma)$ analysis (Zeghal et al., 1995; Elgamal et al., 2005). This is based on the first-order linear interpolation between accelerations at all available depths to estimate stresses and on the second-order interpolation between displacements to evaluate strains for the same depths. Then, the estimated shear stress and strain seismic histories are related with the soil shear stiffness (secant modulus) at each level and thus the $V_{S}$ velocity in cases of low peak ground acceleration recordings. Figure $2 b$ shows the $V_{S}$ velocity distribution with depth for both horizontal components together with their mean value and $\pm 1 \mathrm{std}$. In both components, $\mathrm{V}_{\mathrm{S}}$ values are very similar and quite stable for all soil formations with a small exception for the layers between $55.5 \mathrm{~m}$ and $104.5 \mathrm{~m}$ depths, with less than about $12 \%$ average standard deviation. At greater depths the scatter is quite large (20-35\%) since it is related with the fact that stations are positioned at large intervals (of about $60 \mathrm{~m}$ ). This does not allow computing coherent stress and strain histories, since a) up- and down-going body waves superposed with laterally propagated surface waves from "basin edge" diffractions (Raptakis et al., 2000; Chávez-García et al., 2000) and b) contamination of inverted P- and S-phases at the intermediate interfaces, biasing both the amplitude and frequency content of the first complete period of S-wave with direct consequence on the shape of stress-strain ellipses. Finally, mean $V_{S}$ models from both horizontal components are almost identical, suggesting a rather reliable estimation of an overall mean $\mathrm{V}_{\mathrm{S}}$ profile (Figure $2 \mathrm{~b}$ ), which is very similar to that of seismic interferometry.

Adaptive Simulated Annealing Algorithm (ASA). Another way to analyse data from the vertical array at TST is to use algorithms based on simulated annealing (SA) such as general Monte Carlo approximation methods that allow optimizing problems when a desired global minimum is hidden among many local minima (see details in Chávez-García and Raptakis, 2008). Velocities $V_{P}$ and especially $\mathrm{V}_{\mathrm{S}}$ (at the topmost layers and for frequencies smaller than $5 \mathrm{~Hz}$, in this case) are used in the inversion scheme and they are fixed when synthetic and empirical spectral ratios of 8 earthquakes match. Their good agreement for the radial and transverse components, leads to the $\mathrm{V}_{\mathrm{S}}$ profile of figure 2c. Observed disparities with the previous models, in both velocities and depths, are due to the fact that the thickness of soil layers taken into account in ASA method were a priori determined from the 2D soil model of Raptakis et al. (2000).

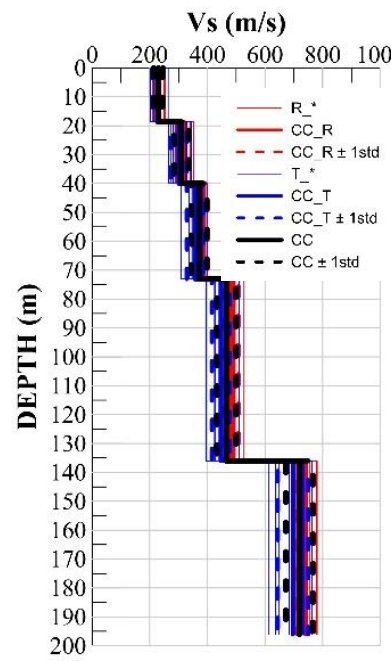

(a)

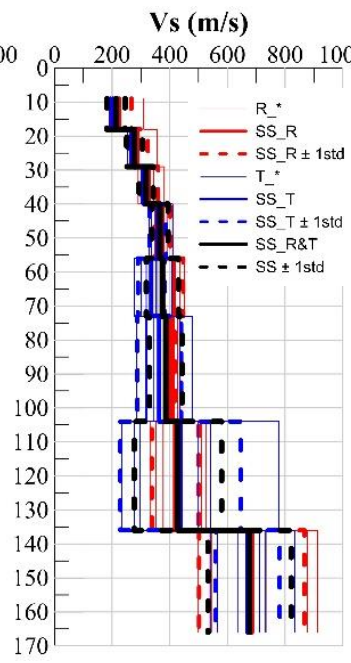

(b)

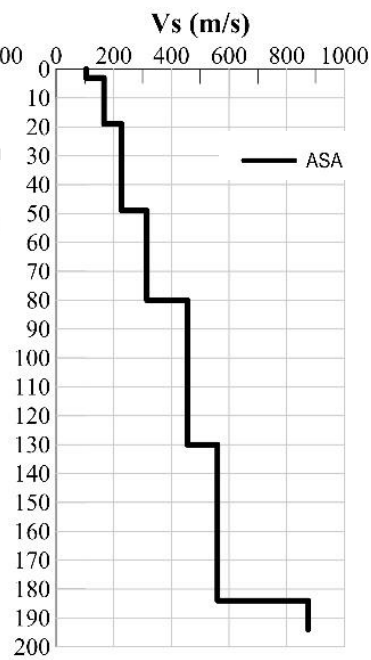

(c)

Figure 1 - Vs profiles from a) interferometry on radial (red lines) and transverse (blue lines) components with their mean value $\mathbf{C C}$ _ $R$ or $\mathbf{C C}$ - $T$ (black lines) and their mean value \pm 1 std (dashed lines) and overall mean $\mathrm{Vs} \pm 1$ std profile $(\mathrm{CC}), \mathrm{b})$ same for stress-strain analysis (SS) and c) ASA. 
Conventional seismic prospecting techniques (CONV). During the last 20 years, many different groups of reversed seismic profiles for seismic prospecting were deployed for short S-wave refraction tests including Love wave inversion analysis, and intermediate and long P-wave refraction tests for Rayleigh wave inversion. This sample of data presents a variety of $\mathrm{V}_{\mathrm{S}}$ profiles. All these surface measurements together with cross-hole $(\mathrm{CH})$ and down-hole $(\mathrm{DH})$ tests are performed in a limited area (of about $0.25 \mathrm{~km}^{2}$ ) around TST site and their analysis led to a total of $26 \mathrm{~V}_{\mathrm{S}}$ profiles (Figure 2). Details could be found in Raptakis and Makra (2015). Field measurements of different lengths, geophone spacings and offsets are performed in order to achieve good resolution $\mathrm{V}_{\mathrm{S}}$ profiles at depths from top to 10-50 m (Figure 2a), and to 140-190 m; i.e. from top to bedrock (Figure 2b). Having in hand all these results, an average $200 \mathrm{~m} \mathrm{~V}$ model is built up taking into account the ability of each analyse to provide detailed layering with regard to their accurate penetration depth. In this manner, average $\mathrm{V}_{\mathrm{S}}$ model down to $16 \mathrm{~m}$ in depth is based on the results of shorter models (SA and SB), following with that of SC group for depths $50 \mathrm{~m}$. For greater depths, the average Vs profile of deeper models is adopted to complete the overall average $V_{S}$ model. This combined model (Figure 2c) shows a successive increase of $\mathrm{V}_{\mathrm{S}}$ values with depth, from about $100 \mathrm{~m} / \mathrm{s}$ to $1200 \mathrm{~m} / \mathrm{s}$, and considerable vertical $\mathrm{V}_{\mathrm{S}}$ changes at $2,4,10,20,40,60,140$ and $180 \mathrm{~m}$ depths with a corresponding increase of the order of $40,17,24,31,25,27,15$, and $26 \%$. At all depths the std is less than $15 \%$ except specific horizons at $15-20 \mathrm{~m}, 50-60 \mathrm{~m}, 120-140 \mathrm{~m}$, and $155-190 \mathrm{~m}$ depth of higher scatter (18-28\%). Meanwhile, the problem to inspect depth and velocity of bedrock remains open.

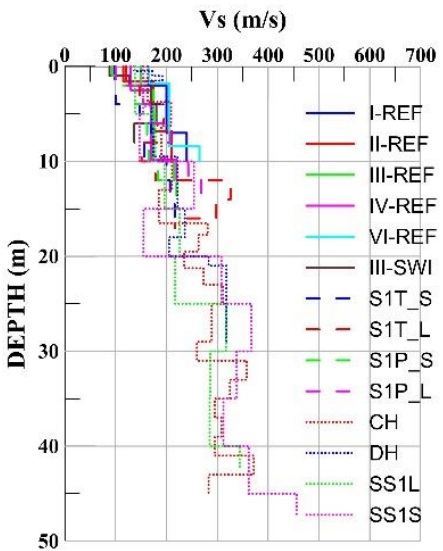

(a)

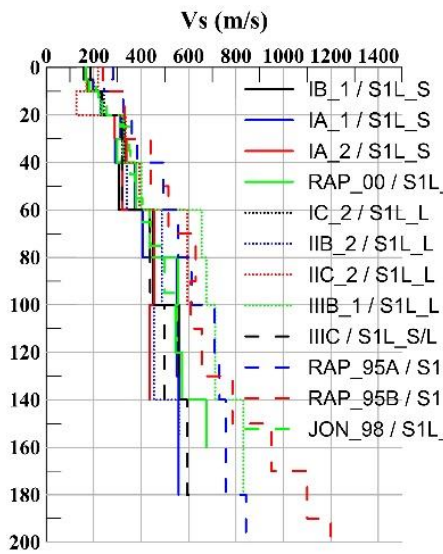

(b)

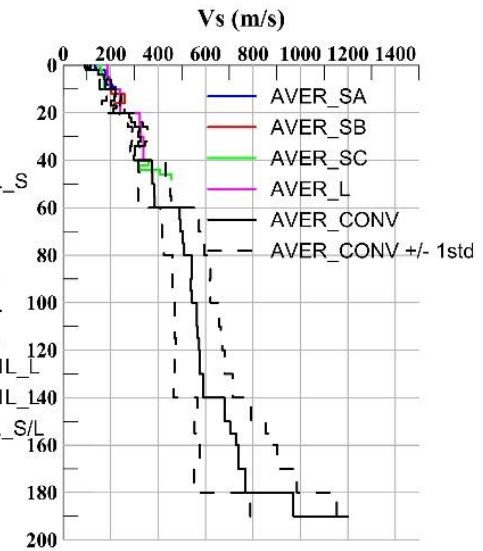

(c)

Figure 2 - a) Near surface $V_{S}$ profiles (14 in total) grouped in 3 sets according to their maximum penetration depth. b) $V_{S}$ profiles ( 12 in total) from SWI and (c) Composite $V_{S}$ profile - CONV (mean values \& mean \pm 1std).

Ambient noise array measurements (AMN). In addition to the above, array microtremor measurements (ANM) were obtained with various scaling of circular arrays in different seasons of the year (Kudo et al., 2002; Apostolidis, 2002) and analysed with Spatial Auto-Correlation coefficient (SPAC) technique (Aki, 1957; Okada, 1998). During the period of measurements, 4 different data sets were acquired. Ambient noise recordings of two sets from different circular arrays - a small of 4 broadband instruments and a large of 7 ones - are analysed to obtain experimental dispersion curves and two different codes to invert them into the corresponding $\mathrm{V}_{\mathrm{S}}$ profiles (Figure 3). The obtained Vs profiles, except one, arise down to $1575 \mathrm{~m}$ depth, where the Vs of $3200 \mathrm{~m} / \mathrm{s}$, that of the intact bedrock, was found. Five new analyses were added to two old published in Apostolidis (2002) and Kudo et al. (2002). All these $\mathrm{V}_{\mathrm{S}}$ models together show significant stability in their resolution depths until $165 \mathrm{~m}$, with an average disparity less than $10 \%$, except for the top 10 $\mathrm{m}$ and between 110 and $120 \mathrm{~m}$ where the observed disparity is slightly larger than $20 \%$. Scatter of similar order is also observed at all depths for the rest of the profile until bedrock with an exception 
close to $185 \mathrm{~m}( \pm 20 \mathrm{~m})$ depth, where it gets the maximum value $(\sim 50 \%)$. At this depth a large impendence contrast between sediments and weathered bedrock is present and the observed scatter could be related with a possible inclination of the sediments-bedrock interface (Manakou et al., 2010). An average $V_{S}$ profile (Figure 3 ) is finally adopted, having in mind that the large array configuration does not allow a detail $\mathrm{V}_{\mathrm{S}}$ distribution at the very surficial layers $(<10-20 \mathrm{~m})$. $\mathrm{V}_{\mathrm{S}}$ variations with depth are larger than $20 \%$ at $10,30,165,190$, and $1575 \mathrm{~m}$.

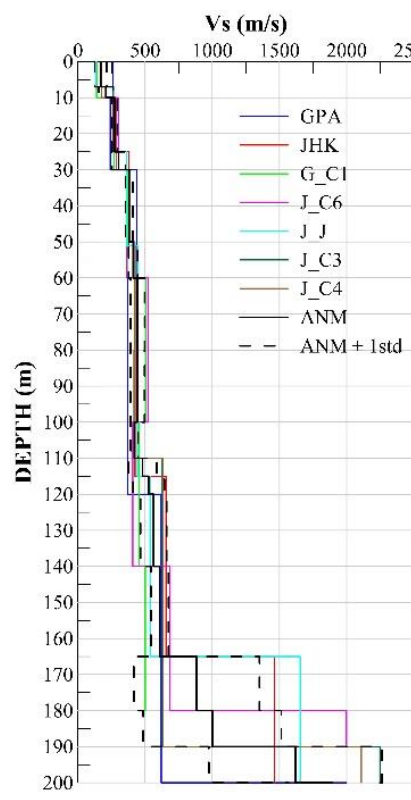

(a)

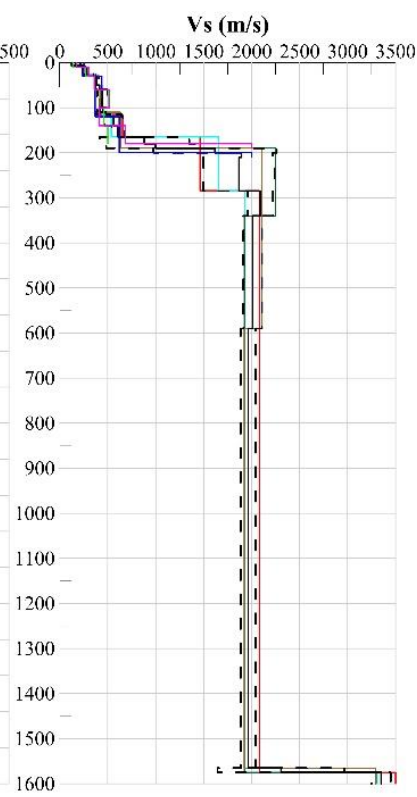

(b)

Figure 3 - Vs profiles (7 in total) from SPAC method, together with their mean \pm 1 std, a) top to $200 \mathrm{~m}$ for sediments, b) from the top to $1600 \mathrm{~m}$ depth.

\section{Comparisons between $V_{S}$ profiles and associated uncertainties}

In this section, we compare mean $\mathrm{V}_{\mathrm{S}}$ profiles provided from a total of 62 different $\mathrm{V}_{\mathrm{S}}$ profiles gathered in five (5) groups (Figure 4). This comparison gives the opportunity to evaluate the differences between $\mathrm{V}_{\mathrm{S}}$ exploration methods. On the other hand, this comparison reveals the different sources of scatter discussed previously. These differences cannot be accounted for as a measure of goodness of one technique relative to the others, but rather as an index of the difference in the principals and assumptions of each method to explore the earth structure; for example the efficiency of methods to detect spatial in-homogeneity of soils (layering stiffness gradient, inclination, and degree of heterogeneity).

The mean CC and SS models, which are based on the analysis of earthquake recordings, have a limitation regarding their efficiency to discern layers of different shear wave velocities with thickness smaller than those fixed at inter-station distances. This fact maybe has its impact on their reliability. Additionally, ASA profile is built based on primary estimations of the sublayers thickness at the site. Moreover, regarding conventional techniques, the inefficiency of the active source capacity to penetrate deep soil horizons in combination with the degree of the soil heterogeneity arises. Layering resolution of the surficial layers of the investigated profiles is related to the consistency of detected wavelengths with measurement configuration (total length, inter-stations and offset distances, source power, etc.). Finally, techniques based on the ambient noise recordings at wide spread arrays (SPAC, ReMi, f-k) fail to explore with high discreteness top soil layers due to inconsistency between small layer thickness and large detected wavelength. Another issue that 
results from the application of the above techniques refers to the observed instability of the interface horizons, which is expressed with a significant scatter $(>20 \%)$ with respect to the averaged $\mathrm{V}_{\mathrm{S}}$ values (Figure 4b). This scatter mostly appears at deep vertical discontinuities (>100 m), where very stiff formations with large impedance contrast do not allow the penetration of sufficient amount of source energy; frequently the latter is trapped within overlying layers.

In general, it has been indicated that techniques, which are based on a single phase of the recording e.g. the very onset $\mathrm{S}$-wave, provide models without significant scatter (interferometry analysis and $\mathrm{SH}$-refraction, $\mathrm{DH}$ and $\mathrm{CH}$ tests). The scatter in both $\mathrm{V}_{\mathrm{S}}$ velocities and interface depths becomes significant, at least at large depths, when more sophisticated techniques were applied that make use time-windows of the recordings, for example an S-wave complete period ( $\tau-\gamma$ ellipses), surface waves (dispersion curves) and transfer functions (ASA). Then, in cases where several techniques can be applied, the user has to select taking into account data in hand, specific aims of the study, and advantages and disadvantages of exploration tools between simplicity and robustness of the models and more sophisticated ones in which layer thickness is a free formed parameter.

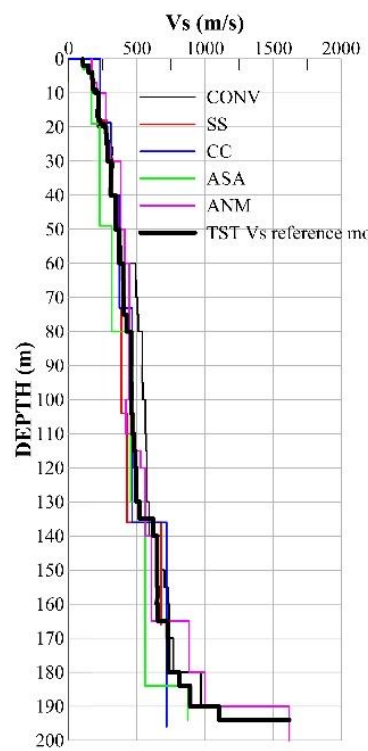

(a)

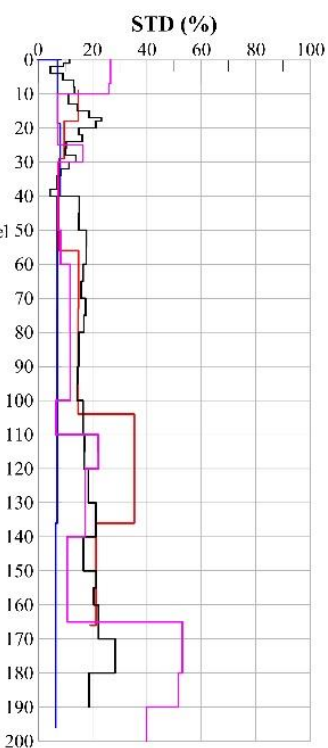

(b)

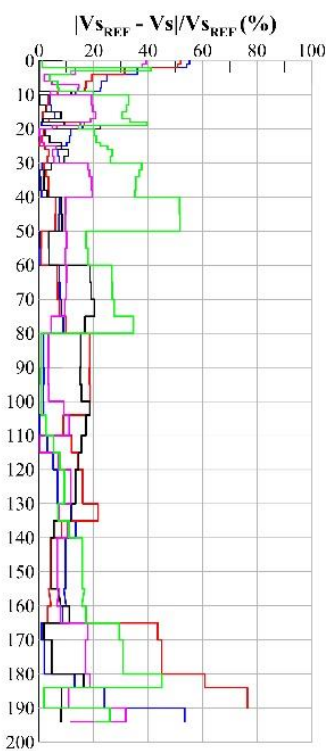

(c)

Figure 4 - a) Reference Vs profile at TST (black line) together with the mean Vs profiles of each method, b) Standard deviation (\%) of mean Vs profiles of each method, c) Disparity (\%) of mean Vs profile of each method with respect to the reference one (right).

To this end, a mean shear wave velocity profile with depth is proposed as reference (REF), in order to be used for the evaluation of the scatter. This reference profile includes all available information balanced in such way to take into consideration imperfections of the results. For example the overall mean $\mathrm{V}_{\mathrm{S}}$ velocities at the surface layer is of about $150 \mathrm{~m} / \mathrm{s}$, which is larger than the originally provided from the short, however more accurate with respect to the thickness of layers and wavelength relationship seismic profiles $\left(\mathrm{V}_{\mathrm{S}} \sim 95 \mathrm{~m} / \mathrm{s}\right)$. In this case we decided to assign the lower value for layers within the first $10 \mathrm{~m}$ (groups SA and SB) because the higher velocity values are a result of low sensitivity methods. Another issue refers to the increase (of an order 10-20\%) of the mean shear wave velocity at 10, 20,40,135, 165, 180, 190, and $\sim 1575 \mathrm{~m}$ depths. However, no significant and unique $\mathrm{V}_{\mathrm{S}}$ contrast is observed, a fact that shows a very heterogeneous stratigraphy of soil mix formations that constrains quite well with the geotechnical description and the $\mathrm{N}_{\mathrm{SPT}}$ values as well as with $\mathrm{V}_{\mathrm{P}}$ velocities from long $\mathrm{P}$-wave refraction seismic profiles (Raptakis et al., 2000). 
This reference profile presents an average quasi-constant scatter (10-20\%), for all depths down 190 $m$ with respect to mean $V_{S}$ profile of each method (Figure 4c). An increase of scatter $(>15-20 \%$ $\max )$ is observed at depths close to intermediate interfaces that are associated with an identified increase of $\mathrm{V}_{\mathrm{S}}$ velocity at 10 and $20 \mathrm{~m}, 30$ and $50 \mathrm{~m}, 60$ and $80 \mathrm{~m}$, and 165 and between 185 and $195 \mathrm{~m}$. Certainly, the fact that this scatter is higher around the interfaces, shows the relative uncertainty of their exact depth. On the other hand, these indications lead us to identify that the observed scatter has at least a remarkable physical or epistemic cause, related with alterations of geological formations. Both scatter and $\mathrm{V}_{\mathrm{S}}$ variation between models and layers, indicate the disparity between the techniques used to investigate the most important parameter in site response analyses. This overall disparity is $17 \%$ for CC, $12 \%$ for SS, $21 \%$ for ASA, $8 \%$ for CONV and $12 \%$ for ANM profile. Thus, a maximum of $20 \%$ disparity could be safely adopted as a realistic bound of the shear wave velocity (Stephenson et al., 2005).

\section{Preliminary site response analysis}

There is a variety of ways to compute site amplification for a given profile. Between them, two principal ways of computations exist; the traditional transfer function and that obtained with the Quarter WaveLength (QWL) approximation (see for details in Boore, 2003). Both of them provide amplification factors as a function of frequency. However, in this study, the QWL approach is applied because it is found to concentrate, compared to the others, the following advantages: i) its outcome has simple shape against the resonant amplification peaks and troughs shaped transfer functions (Figure 5), ii) the quantitative comparison of many different Vs profiles is easier, and iii) its application yields good estimates of high frequency amplification without the constraint of knowing the deep profile, and iv) it is based on the total travel time of the propagated S-wave required by seismic codes and smoothed slowness instead of the measured Vs in the field.

Using QWL technique introduced by Joyner et al. (1981), site amplification A(f) is computed according to the formula $\mathrm{A}(\mathrm{f})=\left[\left(\rho_{\mathrm{B}} \mathrm{V}_{\mathrm{S}, \mathrm{B}}\right)\left(\rho_{\mathrm{S}, \mathrm{AVE}(\mathrm{f})} \mathrm{V}_{\mathrm{S}} \text {, ave(f) }\right)^{-1}\right]^{0.5}$, where $\rho_{\mathrm{B}}$ and $\mathrm{V}_{\mathrm{S}, \mathrm{B}}$ the density and the shear wave velocity of the reference layer of the $V_{S}$ profile (e.g. seismic impedance changes or bedrock). Therefore, for the comparison of site amplification for two or more models the

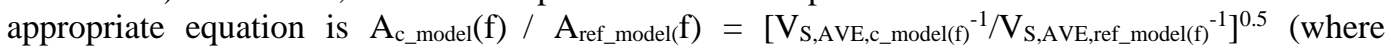
$\mathrm{A}_{\mathrm{c}_{-} \text {model }}(\mathrm{f})$ and $\mathrm{A}_{\text {ref_model }}(\mathrm{f})$ are the amplifications calculated for the model [c_model] assumed to be compared with that considered as reference one [ref_model]. In this case, densities of both models assumed to be the same. In general, the advantages of this technique are sufficiently described in Brown et al. (2002).

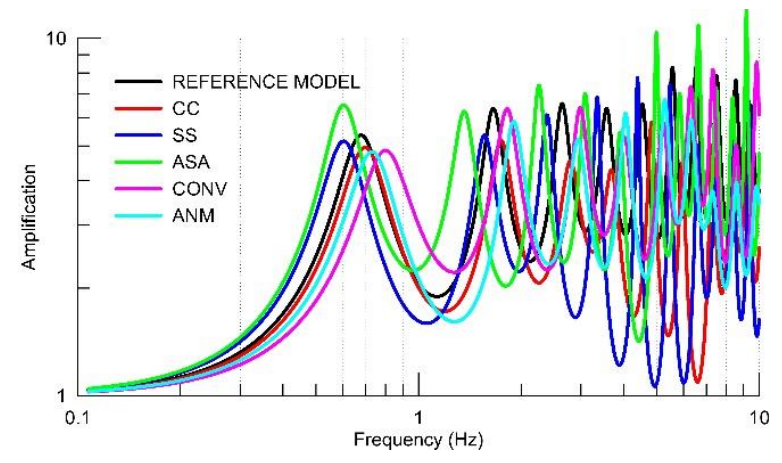

Figure 5 - Transfer functions for reference $V_{s}$ profile with respect to the mean $V_{s}$ profile of each method used.

Results regarding transfer functions depicted in Figure 5 show that the shape and especially the fundamental resonant frequency for all the models is different ranging between 0.6 and $0.8 \mathrm{~Hz}$. All transfer functions calculated using reflectivity method (Kennett, 1983), in the linear-elastic region 
free from any attenuation. However, whether soil attenuation is to be considered then its impact would be for frequencies greater than the fundamental one. Results make clear the difficulty of accepting one of them as the representative for the site. Thus, we proceed with the more suitable QWL technique using SITE_AMP software, developed by Boore (2003). Figure 6a shows the amplification as a function of frequency for all five mean Vs profiles and the reference one. All Vs models independently of their final depth were extended with the Vs velocities provided from the AMN model until a depth reaching intact rock. For simplicity reasons, similarly to traditional transfer functions, attenuation or $\kappa$ factor is not taken into account in the computations, and mass densities were adopted to be the same for all profiles. We observe that CONV, ASA and REF models give a continuously increasing of the amplification factor (between 2.5 and 4.5) up to $10 \mathrm{~Hz}$. While, the rest models (CC, SS, and AMN) for frequencies larger than $3 \mathrm{~Hz}$, amplification is quasi constant of a factor of 3 . These frequencies refer to the contribution of the very surface layers in the amplification. In general, comparing amplification factors derived from both techniques are compatible, since those of QWL technique are the mean of those for the transfer functions (Figure $5)$, at all frequencies of interest.

On the other hand, most $\mathrm{V}_{\mathrm{S}}$ results that come from different techniques are generally compared either in a qualitative way or with statistical single values (average, standard deviation, variance, etc.) for all depths. While these approaches form a common practice in Geotechnical Earthquake Engineering and Engineering Seismology, the interest is recently concentrated to the QWL approximation. Then, knowing the discrepancies between $\mathrm{V}_{\mathrm{S}}$ models with respect to the reference one (REF), we are interested to quantitatively evaluate their differences in terms of site response. To achieve this, the computed amplification of the reference profile is used as the basis relative to which we express the differences in amplification (Figure 6b). Therefore, CC and SS, and AMN curves for frequencies greater than the fundamental one $(0.65 \mathrm{~Hz})$, underestimates $(25 \%, 22 \%$ and $17 \%$ respectively) site amplification with respect to the adopted REF model. The smallest differences in the amplification with respect to the reference model are observed for ASA and CONV profiles ( 3 and 5\% respectively). These differences in amplification is quite analogous with the differences in the $\mathrm{V}_{\mathrm{S}}$ values measured in the uppermost layers expressed by the $\mathrm{V}_{\mathrm{S} 30}$ parameter, namely $21 \%$ for CC, $30 \%$ for SS, $21 \%$ for ANM and $11 \%$ for ASA, $5 \%$ for CONV. This disparity in the amplification of the order $20-25 \%$ is sufficient enough to be cautious against which model could be used to represent soil conditions at the site.
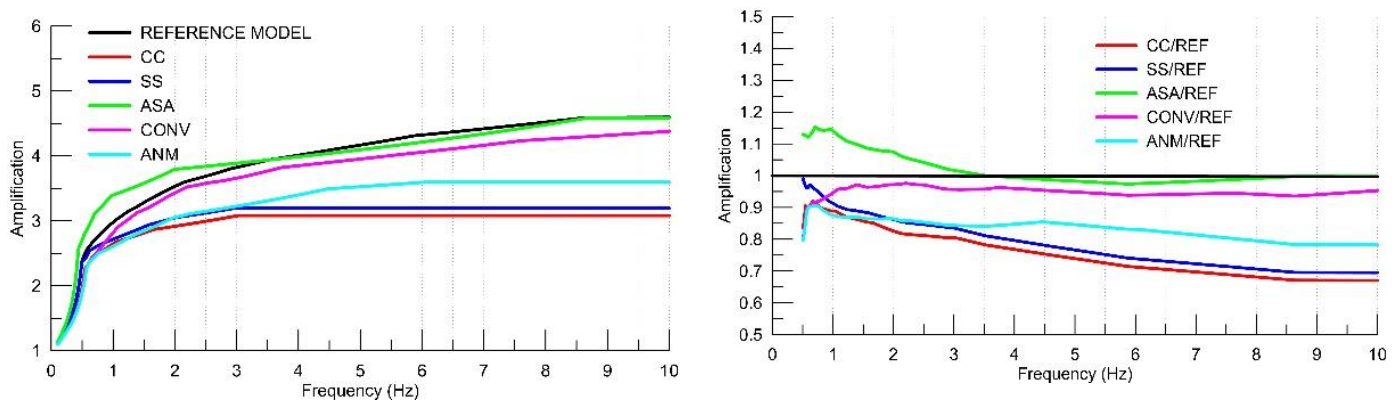

Figure 6 - Amplifications for each averaged $V_{S}$ (left) and relative amplification between averaged models with respect to the reference one (right).

\section{Conclusions}

We have benefited from the availability of $62 \mathrm{~V}_{\mathrm{S}}$ profiles at TST site of Euroseistest site derived from earthquake records, conventional seismic prospecting, and seismic noise array measurements. Five groups of models provided from 9 different invasive and non-invasive methods lead to averaged $\mathrm{V}_{\mathrm{S}}$ profiles. The estimate of $\mathrm{V}_{\mathrm{S}}$ profiles that we obtain differs depending on the technique used. 
However, we cannot discern which one is correct and which is not. We believe that all profiles represent reliable models on the base of the hypotheses and standards of each technique.

The observed scatter of models for each group of measurements is an indication of the uncertainty of the estimate. In general, less scatter is observed at models resulted from the analysis of a single phase (S-wave arrival). In contrast, this scatter becomes significant when the analysis concerns more than one specific phase, such as complete periods of S-wave or surface waves propagated in different modes. However, the techniques based on the S-wave picking have disadvantages (average between fixed receivers or small penetration depth) with respect to those with which a thorough analysis of surface wave results to as deep as possible profiles with layering thickness acting as a free parameter. Moreover, the average of the mean models with their standard deviation is computed. The percentage of standard deviation with respect to the average model albeit is less than $20 \%$ (for techniques based on a single phase of S-wave), this becomes significant at certain depths and is associated with the existence of strong vertical discontinuities, thus introducing an uncertainty on the interface definition between the main formations.

Site amplification for all $\mathrm{V}_{\mathrm{S}}$ profiles was computed with two different techniques; the reflectivity method and the Quarter WaveLength approximation. The different models leads to different transfer functions at least for the shape and the fundamental frequency, as it was to expect. However, no direct comparison between attributes of the amplification can be done. The use of QWL technique aims to investigate the disparity between models in terms of site amplification. Mean $\mathrm{V}_{\mathrm{S}}$ models derived from the various techniques/methods used underestimates site amplification with respect to the reference model by 20-25\%. This disparity is analogous to the differences in the $\mathrm{V}_{\mathrm{S} 30}$ parameter for the mean $V_{S}$ profile of each method with respect to the reference one.

\section{References}

Abrahamson, N., Atkinson, G., Boore, D., Bozorgnia, Y., Campbell, K., Chiou, B., Idriss, I.M., Silver, W. and Youngs, R., 2008. Comparison of the NGA ground-motion relations, Earthq. Spectra, 24, 45-66.

Aki, K., 1957. Space and time spectra of stationary stochastic waves with special reference to microtremors, Bull. Earthq. Res. Inst., 35, 415-456.

Aki, K., 1988. Local site effects on strong ground motion, in Earthquake Engineering and Soil Dynamics II, Proc. Am. Soc. Civil Eng. Geotech. Eng. Div. Specialty Conf., June 27-30, 1988, Park City, Utah, 103-155.

Apostolidis, P., 2002. Determination of the soil structure using microtremors. Application to the estimation of the dynamic properties and the geometry of the soil formations at Thessaloniki city, PhD Thesis (in Greek), Aristotle University of Thessaloniki, Greece.

Bard, P.Y., 1994. Effects of surface geology on ground motion: recent results and remaining issues. In: Proc. 10th Eur. Conf. on Earthq. Engrg, Vienna, August-September 1994, Duma, G., ed., 1, 305-324.

Boore, D.M., 2003. Simulation of ground motion using the stochastic method, Pure Appl. Geophys., 160(3-4), 635-676, doi: 10.1007/ PL00012553.

Boore, D.M., 2004. Can site response be predicted? J. Earthq. Engrg., 8, Special Iss. 1, 1-41.

Borcherdt, R.D., 1970. Effects of local geology on ground motion near San Francisco Bay, Bull. Seismol. Soc. Am., 60, 29-61.

Brown, L.T., Boore, D.M. and Stokoe, K.H., 2002. Comparison of shear-wave slowness profiles at ten strong-motion sites from noninvasive SASW measurements and measurements made in boreholes, Bull. Seismol. Soc. Am., 92, 3116-33.

Chávez-García, F.J., Raptakis, D., Makra, K. and Pitilakis, K., 2000. Site effect at Euroseistest-II. Results from 2D numerical modeling and comparison with observations, Soil Dyn. Earthq. Engrg., 19(1), 23-39.

Chávez-García, F.J. and Raptakis, D., 2008. Inversion of soil structure and analysis of the seismic wavefield from a vertical array, Proc. 14th WCEE, October 12-17, Beijing, China. 
Chávez-García, F.J., 2011. Site effects due to topography and to soft soil layers: Progress made and pending issues. A personal perspective, Proc. 5th ICEGE, January 10-13, Santiago, Chile.

Chávez-García, F.J., Manakou, M. and Raptakis, D., 2014. Subsoil structure and site effects: A comparison between results from SPAC and HVSR in sites of complex geology, Soil Dynamics and Earthquake Engineering, Volume, 57, 133-142.

Douglas, J., Gehl, P., Bonilla, L.F., Scotti, O., Régnier, J., Duval, A.M. and Bertrand, E., 2009. Making the most of available site information for empirical ground-motion prediction, Bull. Seism. Soc. Am., 99, 1502-1520.

Elgamal, A.W., Zcghal, M., Tang, H.T. and Stepp, J.C., 1995. Evaluation of low-strain site characteristics using the Lotung seismic array, J. Geotech. Engrg., 121(4), 350-362.

Hannemann, K., Papazachos, C., Ohrnberger, M., Savvaidis, A., Anthymidis, M. and Lontsi, A.M., 2014. Three-dimensional shallow structure from high-frequency ambient noise tomography: New results for the Mygdonia basin-Euroseistest area, northern Greece, J. Geophys. Res. Solid. Earth, 119, doi: 10.1002/2013JB010914.

Jongmans, D., Pitilakis, K., Demanet, D., Raptakis, D., Riepl, J., Horrent, C., Tsokas, G., Lontzetidis, K. and Bard, P.-Y., 1998. EURO-SEISTEST: determination of the geological structure of the Volvi graben and validation of the basin response, Bull. Seism. Soc. Am., 88, 473-87.

Joyner, W.B., Warrick, R.E. and Fumal, T.E., 1981. The effect of quaternary alluvium on strong ground motion in the Coyote Lake, California, earthquake of 1979, Bull. Seismol. Soc. Am., 71(4), 1333-1349.

Kennett, B.L.N., 1983. Seismic Wave Propagation in Stratified Media. Cambridge University Press, Cambridge, 1983.

Kudo, K., Kanno, T., Okada, H., Sasatani, T., Morikawa, N., Apostolidis, P., Pitilakis, K., Raptakis, D., Takahasi, M., Ling, S., Nagumo, H., Irikura, K., Higashi, S. and Yoshida, K., 2002. Swave velocity structure at EUROSEISTE, Volvi, Greece, determined by the spatial autocorrelation method applied for array records of microtremors, Proc. Earthq. Engrg. Symp., November, Japan, 15-28.

Manakou, M.V., Raptakis, D.G., Chávez-García, F.J., Apostolidis, P.I. and Pitilakis, K.D., 2010. 3D soil structure of the Mygdonian basin for site response analysis, Soil Dyn. and Earthq. Engrg., 30(11), 1198-1211.

Okada, H., 1998. Microtremors as an exploration method: Geo-exploration Handbook, Vol. 2, Society of Exploration Geophysicists of Japan.

Pitilakis, K., Roumelioti, Z., Raptakis, D., Manakou, M., Liakakis, K., Anastasiadis, A. and Pitilakis, D., 2013. The EUROSEISTEST strong ground motion database and web portal, Seismological Research Letters, 84(5), 796-804.

Raptakis, D., Chávez-García, F.J., Makra, K. and Pitilakis, K., 2000. Site effect at Euroseistest-I. Determination of the valley structure and confrontation of observations with 1D analysis, Soil Dyn. Earthq. Engrg., 19(1), 1-22.

Raptakis, D.G., Manakou, M.V., Chávez-García, F.J., Makra, K.A. and Pitilakis, K.D., 2005. 3D configuration of Mygdonian basin and preliminary estimate of its seismic response, Soil Dyn. Earthq. Engrg, 25, 871-887.

Raptakis, D., 2012. Pre-loading effect on dynamic soil properties: Seismic methods and their efficiency in geotechnical aspects, Soil Dyn. Earthq. Engrg., 34, 69-77.

Raptakis, D., 2013. Pre-loading effect on site response. Site amplification and soil properties mismatchk, Soil Dyn. Earthq. Engrg., 53, 1-10.

Raptakis, D. and Makra, K., 2015. Multiple estimates of soil structure at a vertical strong motion array: Understanding uncertainties from different shear wave velocity profiles, Engineering Geology, 192, 1-18. http://dx.doi.org/10.1016/j.enggeo.2015.03.016.

Stephenson, W.J., Louie, J.N., Pullammanappallil, S., Williams, R.A. and Odum, J.K., 2005. Blind shear-wave velocity comparison of ReMi and MASW results with boreholes to $200 \mathrm{~m}$ in Santa Clara Valley: implications for earthquake ground-motion assessment, Bull. Seism.

Zeghal, M., Elgamal, A.W., Tang, H.T. and Stepp, J.C., 1995. Lotung downhole array. II: evaluation of soil nonlinear properties, J. Geotech. Engrg., ASCE, 121(4), 363-378. 